\title{
Clinical and prognostic features of cerebral toxoplasmosis in HIV-infected patients in Lubumbashi, Democratic Republic of the Congo
}

\begin{abstract}
Introduction: Cerebral toxoplasmosis is the main opportunistic infection of the central nervous system (CNS) during in human immunodeficiency virus (HIV)-infection. The purpose of this study is to describe current epidemiologic, clinical, diagnostic, and prognostic features of cerebral toxoplasmosis during HIV-infection in hospital setting in Lubumbashi.

Methods: This descriptive and analytic study examined the records of 21 HIV-positive patients with cerebral toxoplasmosis. Data were collected over 36 months (from January 2015 to December 2017) at the HIV/AIDS Center of Excellence in Lubumbashi (Democratic Republic of the Congo).

Results: Twenty-one patients on 4,283 followed for HIV-infection completed the diagnostic criteria (a prevalence of $0.5 \%$ ) with a sex ratio $(\mathrm{M} / \mathrm{F})$ of 1.3 and a mean age of $41.0 \pm 18.6$ years. Major clinical manifestations were fever $(100 \%)$, headaches $(100 \%)$, motor deficit $(61.9 \%)$, intracranial hypertension $(47.6 \%)$, seizures $(47.6 \%)$, and disorders of consciousness $(42.9 \%)$. Cerebral imaging studies (4 Computed tomography scan) were performed and showed hypodensities with peripheral enhancement by cockade in $75 \%$ of the cases. The mean CD4 T-cell counts was $180.6 \pm 161.9$ cells / mm3. Co-trimoxazole was the main anti-toxoplasma drug in all cases. The lethality rate was $42.9 \%$.
\end{abstract}

Conclusion: Early detection and primary prevention in HIV-infected patients remain essential to improve the prognosis and survival of these patients.

Keywords: cerebral toxoplasmosis, HIV infection, mortality, lubumbashi
Volume II Issue 3 - 202 I

\author{
Joe Kabongo Katabwa, ${ }^{1,2}$ Olivier Mukuku, ${ }^{3}$ \\ Elie Kabika, ${ }^{2}$ Guy Kandja Lwamba, ${ }^{2}$ Charles \\ Wembonyama Mpoy, ${ }^{4}$ André Kabamba \\ Mutombo, ${ }^{5}$ Claude Mulumba Mwamba, ${ }^{1}$ \\ Stanislas Okitotsho Wembonyama ${ }^{2,6}$ \\ 'Department of Internal Medicine, Faculty of Medicine, \\ University of Lubumbashi, Democratic Republic of the Congo \\ ${ }^{2}$ HIV / AIDS Center of Excellence of the University of \\ Lubumbashi, Lubumbashi, Democratic Republic of the Congo \\ ${ }^{3}$ Institut Supérieur des Techniques Médicales, Democratic \\ Republic of the Congo \\ ${ }^{4}$ Department of Obstetrics and Gynecology, Faculty of Medicine, \\ University of Lubumbashi, Democratic Republic of the Congo \\ ${ }^{5}$ Department of Pediatrics, Faculty of Medicine, University of \\ Mbuji-Mayi, Democratic Republic of the Congo \\ ${ }^{6}$ Department of Pediatrics, Faculty of Medicine, University of \\ Lubumbashi, Democratic Republic of the Congo
}

Correspondence: Dr Joe Kabongo Katabwa, Department of Internal Medicine, Faculty of Medicine, University of Lubumbashi, Democratic Republic of the Congo,

Email joekabongo2004@gmail.com

Received: May 18, 2021 | Published: May 31, 202
Abbreviations: AIDS, acquired immuno deficiency syndrome; ART, antiretroviral therapy; CNS, central nervous system; CT, computed tomography; DRC, democratic republic of the congo; HIV, human immunodeficiency virus; MRI, magnetic resonance imaging; PCR, polymerase chain reaction

\section{Introduction}

Toxoplasmosis is a ubiquitous and cosmopolitan parasitosis formerly dreaded in its congenital form. But currently, its cerebral location is at the forefront with the human immunodeficiency virus (HIV) / acquired immunodeficiency syndrome (AIDS) pandemic. ${ }^{1,2}$ It is described as an opportunistic infection of the CNS with a global seroprevalence of Toxoplasma gondii of $44.22 \%$ in people living with HIV according to a meta-analysis made by Safarpour et al. ${ }^{3}$ Cerebral toxoplasmosis has been reported as the most common cause of focal cerebral lesions due to opportunistic infections complicating the course of HIV-infection. ${ }^{4}$ The diagnosis requires quite expensive devices: computed tomography (CT) or cerebral magnetic resonance imaging (MRI), but also the polymerase chain reaction (PCR) in the blood or in the cerebrospinal fluid that has good sensitivity and good specificity.,

Cerebral MRI is the main instrumental method for the diagnosis of cerebral toxoplasmosis, but MRI findings present in the literature are contradictory. Many authors agree only with the fact that etiotropic therapy causes the reduction of MRI anomalies in patients with cerebral toxoplasmosis within 2 weeks. ${ }^{6,7}$ Thus, the therapeutic test with the administration of cotrimoxazole is a diagnostic argument often used in our context where some investigations are not available or inconclusive. ${ }^{8,9}$ In the Democratic Republic of the Congo (DRC), where HIV seroprevalence is $0.8 \%,{ }^{10}$ previous studies have been made on the neuro-infections associated with HIV-infection, thus bringing out the place of cerebral toxoplasmosis among all affections. ${ }^{11-13}$ It is in this context that we have conducted this work which aimed to study the current features of cerebral toxoplasmosis during HIV-infection in hospital setting in Lubumbashi, and to identify risk factors associated with mortality.

\section{Materials and methods}

This was retrospective study carried out on files of the patients received at the HIV / AIDS Center of Excellence of the University of Lubumbashi (CE-UNILU) at the Jason Sendwe hospital between January 2015 and December 2017.

Have been included all patients in hospitalized in the CE-UNLU, in which the final diagnosis of cerebral toxoplasmosis was placed on the basis of the evocative clinical signs, laboratory investigations (serological detection of $T$. gondii-specific IgG and IgM antibodies in the blood serum with ELISA, hyperproteinorachia), radiological findings (cerebral imagings of toxoplasmosis when available) and a favorable evolution under anti-toxoplasma drug.

In cases where laboratory investigations did not confirm the diagnosis despite a strongly evocative clinic, a therapeutic test at cotrimoxazole made it possible to conclude. For each HIV-infected 
patient, we have collected (from the hospitalization file) the following data: age, sex, prophylaxis, antiretroviral therapy (ART), clinical signs, CD4 T-cell counts, toxoplasmic serology, hemoglobin levels, neuroimagings (when available) and prognostic of the disease. These data were analyzed with the EPI Info 7.2 software. The Chi-Square test and the exact Fisher test for the comparison of the proportions were used. A value of $p<0.05$ was considered statistically significant.

\section{Results}

During the study period, 4,283 HIV-infected patients were admitted to CE-UNLU, including 21 cases of diagnosed cerebral toxoplasmosis, a prevalence of $0.5 \%$. In admission, $11(52.4 \%)$ patients had their HIV serological status already known and were already under chemoprophylaxis at cotrimoxazole and under antiretroviral therapy (ART) since a mean of $12.6 \pm 7.1$ months. Cerebral toxoplasmosis was the circumstance of the discovery of HIV-infection in $47.6 \%$ of the cases. The mean age of the patients was $41.0 \pm 18.6$ years (range: 15 and 70 years). There was a male predominance, with a sex ratio (M / F) of 1.3 .

Clinical signs were dominated by fever (100\%), headaches $(100 \%)$, motor deficit (61.9\%), intracranial hypertension $(47.6 \%)$, seizures $(47.6 \%)$, and disorders of consciousness $(42.9 \%)$ (Table 1). Focal signs were at type of hemiplegia (six patients) and facial paralysis (two patients). Bergman triad associating fever, intracranial hypertension and focal sign was found in two patients.

Table I Distribution of cerebral toxoplasmosis patients by age, sex, and clinical signs

\begin{tabular}{lll}
\hline Variable & $\begin{array}{l}\text { Number } \\
(\mathbf{n}=\mathbf{2} \mathbf{1})\end{array}$ & Percentage \\
\hline Age & 3 & 14,3 \\
$<20$ years & 2 & 9,5 \\
$20-29$ years & 6 & 28,6 \\
$30-39$ years & 2 & 9,5 \\
$40-49$ years & 5 & 23,8 \\
$50-59$ years & 3 & 14,3 \\
$\geq 60$ years & & \\
Sex & 9 & 42,8 \\
Female & 12 & 57,2 \\
Male & & \\
Clinical signs & 21 & 100 \\
Fever & 21 & 100 \\
Headaches & 13 & 61,9 \\
Motor deficit & 10 & 47,6 \\
Intracranial hypertension & 10 & 47,6 \\
Seizures & 9 & 42,9 \\
Disorders of consciousness & 9 \\
\hline
\end{tabular}

In addition to cerebral toxoplasmosis, all patients presented neuromeningeal cryptococcosis; 3 patients had pulmonary tuberculosis and 2 had an ophthalmic zona. Brain CT scan was made in 4 patients and had mainly shown hypodensities with peripheral enhancement by cockade in $75 \%$ of the cases.
Anemia was found in $42.9 \%$ of the cases with a mean hemoglobin rate of $10.1 \pm 3.2 \mathrm{~g} / \mathrm{dL}$. The mean CD4 T-cell counts was $180.6 \pm 161.9$ cells / mm3 and $57.1 \%$ of the cases had a CD4 rate of less than 200 cells $/ \mathrm{mm}^{3}$. Cotrimoxazole (sulfamethoxazole $800 \mathrm{mg}$ - thrimethoprim $160 \mathrm{mg}$, tablet) was used in all patients (2 tablets three times a day). The secondary prophylaxis has been started in 12 patients $(57.1 \%)$ having favorable outcome under cotrimoxazole attack treatment for a period that varied in our study between 1 and 24 months until the immune restoration.

The mean duration of hospital stay was $19.5 \pm 11.2$ days. Over the twenty-one cases, we observed 9 deaths, a hospital lethality of $42.9 \%$. As shown in Figure 1, none of the variables studied had influenced the lethality $(\mathrm{p}>0.05)$.

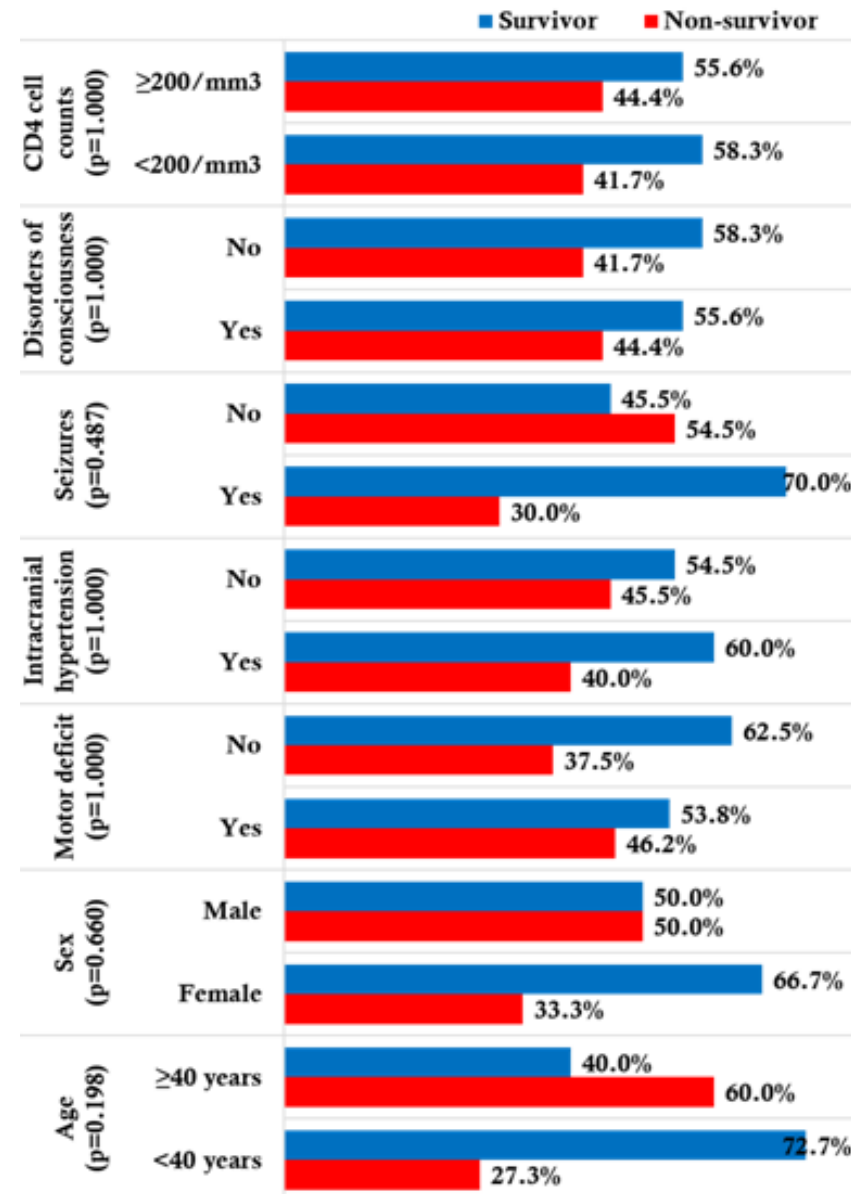

Figure I Factors associated with death during cerebral toxoplasmosis.

\section{Discussion}

Cerebral toxoplasmosis prevalence has decreased considerably with the advent of ART and the introduction of cotrimoxazole prophylaxis. ${ }^{1}$ However, in our study, we collected 21 cases over a period of three years (2015-2017). In our series, the hospital prevalence of cerebral toxoplasmosis was $0.5 \%$. It is lower than those noted in other African series ranging from $2.2 \%$ to $17.5 \%{ }^{14-19}$ This low frequency in our study would be explained by a late diagnosis of HIVinfection, a non-respect of primary prophylaxis with cotrimozaxole in some people, the lack of cheap screening and diagnostic tools. To these add the financial difficulties of patients because, since they take care of themselves, some of them die even before the diagnosis is posed. 
Although computed tomography has been available since 2000 its accessibility and systematic achievement in all patients with focal syndrome remains impossible in our environment. The mean age of our patients $(41.0 \pm 18.6$ years $)$ is consistent with those found in literature ranging from 38 to 41.5 years. ${ }^{17,19}$ This mean age could be explained by the fact that HIV-infection reaches the younger population.

Cerebral toxoplasmosis was the circumstance in which HIVinfection was found in $47.6 \%$ of patients; this rate was $58 \%$ in the study of Cissoko et al. ${ }^{19}$ The delay in diagnosis of HIV infection is a major obstacle to the optimal management of this affection. For this reason, screening policies, as well as clinical management strategies for these patients, need to be revised to reduce HIV-infection related morbidity and mortality. Clinically, the majority of our patients had a febrile focal neurological picture. Regarding the frequency of symptoms including fever (100\%), headache (100\%) and motor deficit $(61.9 \%)$, we noted a similarity with many studies. ${ }^{15,17,19}$ However, the percentage of patients with impaired consciousness (42.9\%) was higher than in other series: $30.8 \%$ in Togo ${ }^{15}$ and $38 \%$ in Morocco. ${ }^{17}$

The enzyme-linked immunosorbent assay (ELISA) of IgM against the antigen of Toxoplasma gondii is also effective in distinguishing between infection and active toxoplasmosis in the immunocompromised..$^{20}$ In our series, toxoplasmic serology had returned positive to $\operatorname{IgM}$ and the outcome under cotrimoxazole was favorable, confirming the diagnosis. Toxoplasmic serology, including the IgG assay, is insensitive to the diagnosis of active toxoplasmosis. Our diagnostic approach combining the clinical epidemiological context, toxoplasmic serology, computed tomography (where available) and therapeutic testing has resulted in a wide recruitment of cerebral toxoplasmosis cases. This approach is consistent with the recommendations of the Modi et al. ${ }^{21}$ on the management of focused brain lesions associated with HIV infection in low-income countries. Severe immunosuppression in our series (mean CD4 cell count 180.6 cells $/ \mathrm{mm} 3$ and $57.1 \%$ of the cases with CD4 cell count $<200$ cells $/ \mathrm{mm} 3$ ) is comparable to the literature that reports that cerebral toxoplasmosis occurs most often when CD4 cell count is less than 200 cells $/ \mathrm{mm}^{3}{ }^{1,17-19}$

Clinical improvement was observed in 12 patients (57.1\%). The lethality rate recorded in our series $(42.9 \%)$ is close to that reported by Cissoko et al..$^{19}(58 \%)$; but higher than those noted by Lahoucine et al. ${ }^{17}(28.6 \%)$ and Bamba et al. ${ }^{22}(16.7 \%)$. This overmortality is due in part to the advanced clinical stage of our patients and the combination of other opportunistic infections. Toxoplasmosis associated with HIV infection remains a major cause of death, probably underestimated. Reasons may include advanced clinical HIV infection prior to treatment due to late screening, exposure to multiple potential opportunistic pathogens in a tropical environment.

\section{Conclusion}

Cerebral toxoplasmosis remains among the opportunistic infections of the CNS encountered during HIV infection in Lubumbashi. Its diagnosis remains based on a bundle of clinical, computed tomography and therapeutic arguments. Lethality remains high. Because of the high risk of developing cerebral toxoplasmosis, anti-toxoplasma chemoprophylaxis should be widely prescribed in HIV-infected patients with positive toxoplasmic serology.

\section{Acknowledgments}

None.

\section{Competing interest}

The authors declare that they have no competing interests.

\section{Funding}

None.

\section{References}

1. Azovtseva OV, Viktorova EA, Bakulina EG, et al. Cerebral toxoplasmosis in HIV-infected patients over 2015-2018 (a case study of Russia). Epidemiology \& Infection. 2020;148:e142.

2. Basavaraju A. Toxoplasmosis in HIV infection: An overview. Tropical parasitology. 2016;6(2):129-135.

3. Safarpour H, Cevik M, Zarean M, et al. Global status of Toxoplasma gondii infection and associated risk factors in people living with HIV. Aids. 2020;34(3):469-474

4. Nissapatorn V. Toxoplasma gondii and HIV: A never-ending story. The Lancet HIV. 2017;4(4):e146-e147.

5. Mesquita RT, Ziegler AP, Hiramoto RM, et al. Real-time quantitative PCR in cerebral toxoplasmosis diagnosis of Brazilian human immunodeficiency virus-infected patients. J Med Microbiol. 2010;59:641-647.

6. Christian Eggers, Gabriele Arendt, Katrin Hahn, et al. HIV-1-associated neurocognitive disorder: epidemiology, pathogenesis, diagnosis, and treatment. J Neurol. 2017;264(8):1715-1727.

7. Victoria Aramă, Raluca Mihăilescu, Mihaela Rădulescu, et al. Clinical relevance of the plasma load of cytomegalovirus in patients infected with HIV - a survival analysis. J Med Virol. 2014;86(11):1821-1827.

8. Millogo A, Sawadogo AB, Lankoande D, et al. Problèmes diagnostiques des processus expansifs intracra niens chez les patients infectés par le VIH au Centre Hospitalier de Bobo-Dioulasso (Burkina Faso). Bull Soc Path Exot. 2001;94(4):315-318

9. Finielz P, Chuet C, Ramdame M, et al. Traitement de la toxoplasmose cérébrale au cours du sida par le Cotrimoxazole. Press Med 1995;24=:917.

10. Programme National Multisectoriel de lutte contre le Sida (PNMLS). Rapport national de suivi de la riposte au VIH/Sida. PNMLS: Kinshasa; 2020.

11. Kabongo JK, Mutape B, David K, et al. Causes of Deaths of HIV Infected Patients at the HIV/AIDS Center of Excellence of the University of Lubumbashi in Lubumbashi, Democratic Republic of Congo. J Infect Dis Med. 2017;2(3):120.

12. Mbula MMK, Situakibanza HNT, Mananga LG, et al. Profil clinique et biologique des personnes vivant avec le VIH/SIDA suivies dans le Service des Maladies Infectieuses des Cliniques Universitaires de Kinshasa (République Démocratique du Congo). Rev Mali Infect Microbiol. 2020;15:21-29.

13. Katabwa JK, Mukuku O, Lwamba GK, et al. Neuromeningeal cryptococcosis in HIV-infected patients in Lubumbashi, Democratic Republic of the Congo. J Neurol Stroke. 2021;11(3):73-77.

14. Avoide DG, Adjien C, Houinato D, et al. Cerebral toxoplasmosis in hospital environment at cotonou (benin). AJNS. 2005;24(2):48-55.

15. Goita D, Karambe M, Demble JP, et al. Toxoplasmose cérébrale au cours du SIDA dans le service des maladies infectieuses du CHU du point G, Bamako-Mali. Mali medical. 2012;27(1):47-50.

16. Sow MS, Sylla K, Cissé D, et al. Pronostic Factors of Cerebral Toxoplasmosis in Department of Infectious and Tropical Diseases at Donka National Hospital. Advances in Infectious Diseases. 2019;9:243251. 
17. Lahoucine $\mathrm{T}$, Idalene $\mathrm{M}$, Ihbibane $\mathrm{F}$, et al. Cerebral toxoplasmosis in patients infected with Human immunodeficiency virus in Morocco. Revue Francophone des Laboratoires. 2016;2016(487):78-82.

18. Kadjo K, Ouattara B, Kra O, et al. Toxoplasmose cérébrale chez le sidéen dans le service de médecine interne du CHU de Treichville. Méd Af Noire. 2007;5401:13-16.

19. Cissoko Y, Seydi M, Fortes Deguenonvo L, et al. Current profile of cerebral toxoplasmosis in a hospital setting in Dakar. Med Sante Trop. 2013;23(2):197-201.

20. Araujo PR, Ferreira AW. High diagnostic efficiency of IgM-ELISA with the use of multiple antigen peptides (MAP1) from T. gondii ESA (SAG1, GRA-1 and GRA-7), in acute toxoplasmosis. Rev Inst Med Trop Sao Paulo. 2010;52:63-68.
21. Modi M, Mochan A, Modi G. Management of HIV-associated focal brain lesions in developing countries. QJM: An International Journal of Medicine. 2004;97(7):413-421.

22. Bamba S, Zoungrana J, Nikièma Z, et al. Impact of alternative treatment approach for cerebral toxoplasmosis among HIV/AIDS patients from a resource-poor setting in Burkina Faso. Ann parasitol. 2017;63(3):173181. 